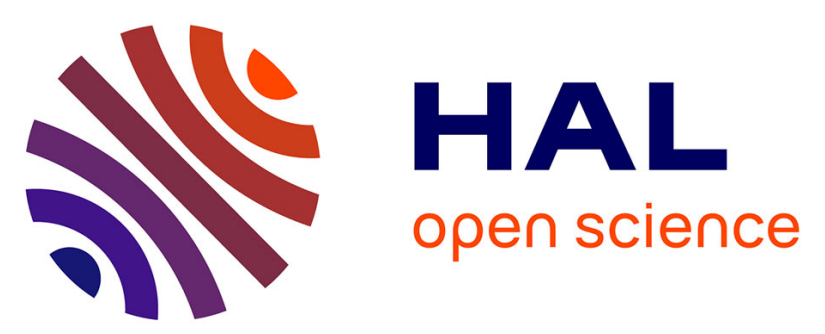

\title{
'Warming up' a wind instrument: the time-dependent effects of exhaled air on the resonances of a trombone
}

Henri Boutin, John Smith, Joe Wolfe

\section{To cite this version:}

Henri Boutin, John Smith, Joe Wolfe. 'Warming up' a wind instrument: the time-dependent effects of exhaled air on the resonances of a trombone. Journal of the Acoustical Society of America, 2020, 148 (1817). hal-03020266

\section{HAL Id: hal-03020266 \\ https://hal.sorbonne-universite.fr/hal-03020266}

Submitted on 23 Nov 2020

HAL is a multi-disciplinary open access archive for the deposit and dissemination of scientific research documents, whether they are published or not. The documents may come from teaching and research institutions in France or abroad, or from public or private research centers.
L'archive ouverte pluridisciplinaire HAL, est destinée au dépôt et à la diffusion de documents scientifiques de niveau recherche, publiés ou non, émanant des établissements d'enseignement et de recherche français ou étrangers, des laboratoires publics ou privés. 
'Warming up' a wind instrument: the time-dependent effects of exhaled air on the resonances of a trombone

\section{Running title: 'Warming up' a wind instrument}

Henri Boutin, ${ }^{1}$ John Smith ${ }^{2}$ and Joe Wolfe ${ }^{2}$

1STMS (UMR9912), Sorbonne Université, Ircam, CNRS, 1, place Igor Stravinsky, 75004, Paris, France

${ }^{2}$ School of Physics, UNSW Sydney, 2052, Australia

Keywords: brass instrument, warming up, wind instrument, temperature, pitch

\footnotetext{
1) Author to whom correspondence should be addressed. Electronic mail: boutin@ircam.fr
} 


\section{ABSTRACT}

To study the effect of 'warming up' a wind instrument, the acoustic impedance spectrum at the mouthpiece of a trombone was measured after different durations of playing. When an instrument filled with ambient air is played in a room at $26-27^{\circ} \mathrm{C}$, the resonance frequencies initially fall. This is attributed to $\mathrm{CO}_{2}$ in the breath initially increasing the density of air in the bore and more than compensating for increased temperature and humidity. Soon after, the resonance frequencies rise to near or slightly above the ambient value as the effects of temperature and humidity compensate for that of increased $\mathrm{CO}_{2}$. The magnitudes and quality factors of impedance maxima decrease with increasing playing time whereas the minima increase. Using the measured change in resonance frequency, it proved possible to separate the changes in impedance due to changes in density and changes in acoustic losses due to water condensing in the bore. When the room and instrument temperature exceed $37{ }^{\circ} \mathrm{C}$, condensation is not expected and, experimentally, smaller decreases in magnitudes and quality factors of impedance maxima are observed. The substantial compensation of the pitch fall due to $\mathrm{CO}_{2}$ by the rise due to temperature and humidity is advantageous to wind players.

\section{INTRODUCTION}

Players of wind instruments 'warm up' their instruments by playing or breathing into them before tuning: they know that, all else equal, a cold, dry instrument usually plays at lower pitch than it does when filled with warm, humid, exhaled air. During extended sections of rests in ensemble music, they often breathe quietly into the instrument to warm it to ensure that, on reentry, they will be playing an instrument already filled, at least partly, with warm, humid, exhaled air.

The speed of sound in air increases with increasing temperature and humidity and decreases with the increasing concentration of $\mathrm{CO}_{2}$. (The expansion of the instrument itself 
over the small temperature change produced by playing is negligible.) Consequently, and all else equal, increased temperature and humidity raise the frequencies of resonances and thus the pitch of notes played. Increases in playing pitch of 1.2 to 2.6 cents per ${ }^{\circ} \mathrm{C}$ increase in temperature are reported for brass instruments (Young, 1946). The increase in $\mathrm{CO}_{2}$ during playing of a phrase would be expected, all else equal, to lower the pitch, while humidity is expected to increase it (see calculations by Fuks, 1996; Balasubramanian and Kausel, 2015). Measurements on (already warm) oboe and bassoon show decreases in pitch of order 10 cents ( $0.6 \%$ in frequency) in the $10 \mathrm{~s}$ of playing following inhalation; these are attributed to increased $\mathrm{CO}_{2}$ concentration (Fuks, 1997).

To a non-musician, effects of less than one percent (the size of the effects reported here) may seem small, but to a musician, one percent is a sixth of a semitone and, for a sustained note, an important error in intonation.

By adjustment of blowing pressure and other control parameters that players would include in the term 'embouchure', players of modern brass instruments can 'lip up or down', i.e. raise or lower the pitch over a total range of roughly two semitones (Boutin et al., 2020) and thus can usually correct quickly for expected or heard errors in intonation. (Trombonists also have the slide available.) Consequently, simple measurements of the played pitch, especially for experienced musicians, are not expected to reveal the effects of breath composition or temperature in the absence of compensation. Nevertheless, it is interesting for both scientists and musicians to know the magnitude of these effects.

There have been several previous measurements of the input impedance of a trombone filled with cool, dry air (e.g. Backus, 1976; Caussé et al., 1984; Braden et al., 2009). One of the motivations for the present study is that knowledge of the impedance in playing conditions can allow determination of the acoustic flow into the instrument (Boutin et al., 2015; 2020). 
This paper reports measurements of the impedance spectrum of the bore of a trombone, initially filled with dry, ambient air, but then played for differing durations. A preliminary set of measurements was briefly reported previously (Boutin et al. 2013) as part of a different study. Those results are reanalyzed here, as are a more detailed set of results over a larger range of conditions. All but one set of measurements were made at room temperature (between $26{ }^{\circ} \mathrm{C}$ and $27{ }^{\circ} \mathrm{C}$ ). The other set was made in a laboratory heated to $39{ }^{\circ} \mathrm{C}$ so as to avoid the effect of condensation of water in the bore of the instrument.

\section{MATERIALS AND METHODS}

\section{A. The instrument}

The trombone (Yamaha YBL 321) and a modified mouthpiece were used and described in a previous study (Boutin et al., 2015). The mouthpiece had the same volume and rim diameter as a normal mouthpiece but was modified for other experiments conducted at the same time. The Bb-F 'trigger' mechanism was used in its shorter configuration and the main slide had its minimum length throughout. Players call this 'first position': it is used to play notes in an incomplete harmonic series, including Bb2 (nominally $117 \mathrm{~Hz}$ at $\mathrm{A} 440$ ), $\mathrm{F} 3, \mathrm{~B} b 3$, D4 etc. The tuning slide was maintained at $18 \mathrm{~mm}$ from its shortest position (a typical position for playing at A440). The player for the detailed study was the first author, who has very limited experience playing the trombone, but has no unusual respiratory issues and plays with an air flow rate typical of experienced players (Boutin et al., 2015). For the larger preliminary study, measurements were made on three more additional players two of whom had orchestral or band experience on brass and one of whom was a beginner. For the data reported here, no measurements were made of the players-only of the instrument, after different periods of being played. 


\section{B. The trombone input impedance}

The input impedance of the trombone bore, called $Z_{\text {bore }}$, was measured using an impedance head mounted in a plane plate that was sealed to the rim of the mouthpiece with petroleum jelly (Boutin et al., 2015). An acoustic current source was located next to a microphone (4944A, Brüel \& Kjær, Denmark) connected to a pre-amplifier and a FireWire audio interface (MOTU 828, Cambridge, MA), see Fig. 1. This impedance head (Smith et al., 1997) was calibrated by measuring the impedance of an acoustically infinite duct, $142 \mathrm{~m}$ long and $7.8 \mathrm{~mm}$ diameter. The broadband signals used for calibration and measurement were sums of sine waves between $50 \mathrm{~Hz}$ and $1.8 \mathrm{kHz}$, with a spacing of $0.67 \mathrm{~Hz}\left(=44.1 \mathrm{kHz} / 2^{16}\right)$ corresponding to a time window lasting $1.5 \mathrm{~s}$. This was a compromise between resolution in frequency and time; the $0.67 \mathrm{~Hz}$ frequency resolution allowed accurate determination of the maxima and minima, whilst the $1.5 \mathrm{~s}$ time resolution was needed for the extrapolation of measurements back to the cessation of playing. Measurements were conducted in a lab at temperature of $26.3 \pm 0.3{ }^{\circ} \mathrm{C}$ and $55 \pm 6 \%$ relative humidity, except for one series. That series was conducted with the temperature of the laboratory and the trombone raised to $39 \pm 2{ }^{\circ} \mathrm{C}$ with relative humidity $45 \pm 6 \%$. This temperature was chosen to avoid water condensation in the bore of the instrument when played.

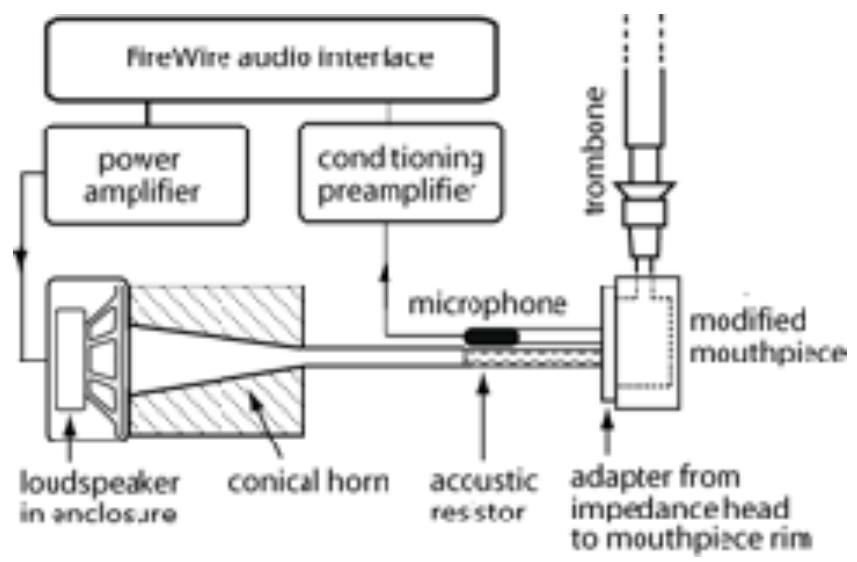


FIG. 1. Schematic (not to scale) of the impedance spectrometer used to measure $Z_{\text {bore }}(f)$ for the trombone.

The instrument was initially at ambient temperature and flushed with ambient air and equilibrated in the lab at ambient temperature and humidity. The impedance head was connected to the mouthpiece and the input impedance was measured before each note was played. The trombone was then played for a predetermined duration. For the $3 \mathrm{~s}$ and $10 \mathrm{~s}$ measurements, a single sustained note was played. For the $30,60,120$ and $240 \mathrm{~s}$ measurements, the player played long notes but briefly inhaled as needed. The slide was left in first position and the player mainly played the first two notes of the harmonic series $(\mathrm{B} b 2$ and F3). The impedance head was then connected and an impedance measurement started within $3 \mathrm{~s}$ of the cessation of playing; each impedance measurement comprised 32 cycles of $2^{16}$ samples at $44.1 \mathrm{kHz}$, consequently each cycle lasted $1.49 \mathrm{~s}$ and the total measurement lasted $48 \mathrm{~s}$. The instrument was then flushed with ambient air. This protocol of a measurement before and after each playing was repeated three times for each note duration. Thus 36 impedance measurements were obtained at $26.3^{\circ} \mathrm{C}$ and another 28 at $39^{\circ} \mathrm{C}$.

The measurement of each cycle took $1.49 \mathrm{~s}$ and this limits the frequency resolution. Because the proportional change is of interest here, the resulting uncertainty has a greater effect on the low-frequency impedance peaks. On the other hand, the eighth and higher peaks are weaker and so less sharp, see Fig. 3a, which introduces uncertainty at high frequencies. Analysis showed that peaks three to seven gave least variance among measurements. (These also fall towards the middle of the instrument's range: the first peak is not used, and those above the eighth are rarely used.) In the following analysis, averages over the third to seventh peaks are used.

Around each maximum and minimum of each impedance measurement, a cubic spline 
interpolation was used to achieve a frequency resolution of $0.1 \mathrm{~Hz}$. The associated Q factor is estimated as the ratio between the peak frequency and its 3-dB bandwidth. A finer cubic spline interpolation with a frequency resolution of $0.001 \mathrm{~Hz}$ was used to achieve a precision lower than 0.01. The frequency and magnitude of each impedance maximum and minimum and the Q factor of each impedance maximum were then calculated for each cycle of the measurement. The values at the moment when playing ceased (i.e. $3 \mathrm{~s}$ before the first cycle of measurement) were determined by linear regression over the following 32 contiguous cycles during the measurement period, as shown by the extrapolations to $t=0 \mathrm{in} \mathrm{Fig.} \mathrm{2.} \mathrm{Note} \mathrm{that} \mathrm{the}$ magnitudes of the minima (especially those after $240 \mathrm{~s}$ of playing) are more scattered from cycle to cycle than the other data. This may be due to the difficulty of quickly measuring the magnitudes of the impedance minima with a variation less than $1 \%$ in a duct with water condensing on the walls. (The magnitudes of the minima and maxima are taken from the same measurement of $Z_{\text {bore }}(f)$ and the minima are typically about 30-40 times smaller than the maxima-see Fig. 3-with a corresponding decrease in measured precision).
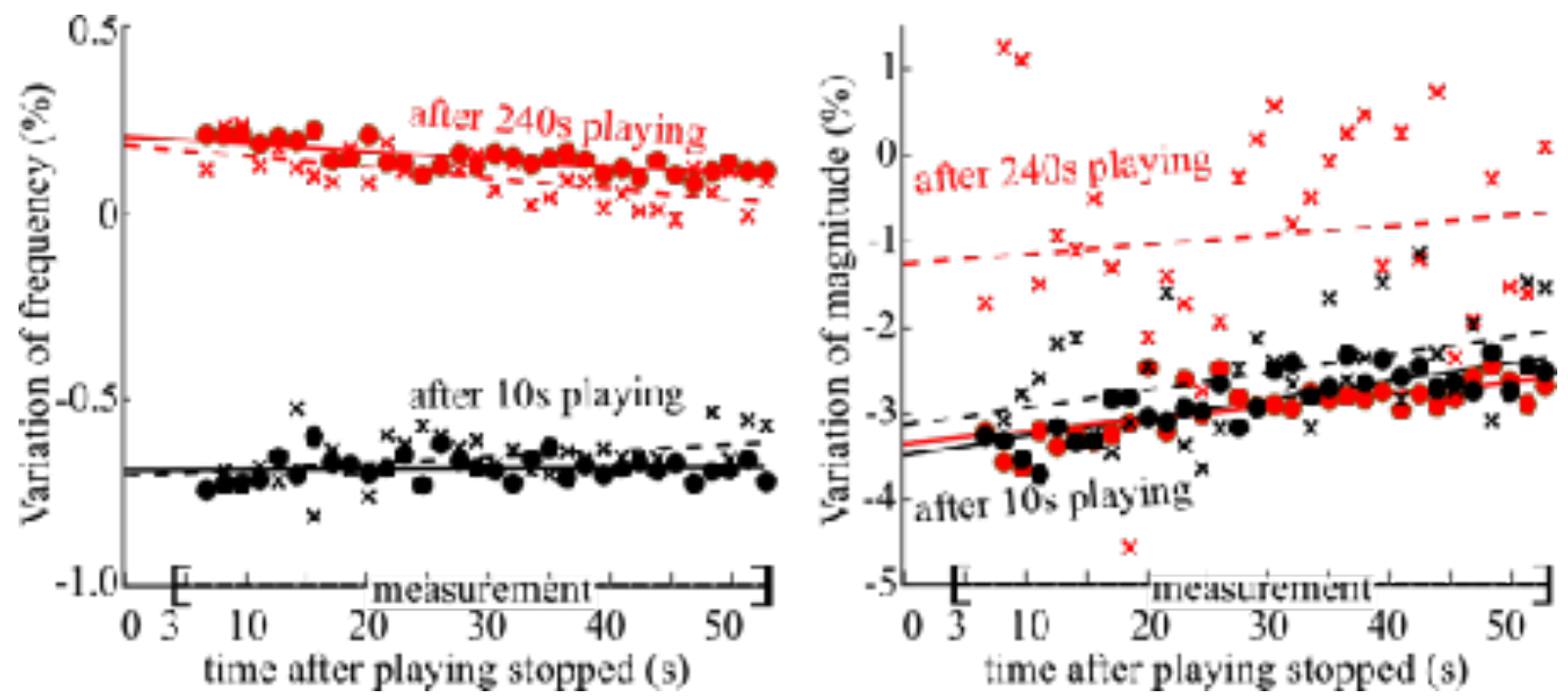

FIG. 2. (Color online) Examples of the extrapolation procedure used to estimate the percentage changes in the frequencies $f_{\max }$ and $f_{\min }$, and the magnitudes $Z_{\max }$ and $Z_{\min }$ of the extrema in $Z_{\text {bore }}$ at the moment playing ceased $(t=0)$. The percentage variations in 
frequency (left) and magnitude (right) of the impedance maxima and minima over the measurement period are relative to the values measured before playing started. Circles indicate the average values of maxima 3 to $7(169 \mathrm{~Hz}$ to $405 \mathrm{~Hz})$ for each cycle and the crosses indicate the average values of minima 3 to $7(195 \mathrm{~Hz}$ to $439 \mathrm{~Hz})$. The black symbols correspond to a playing duration of $10 \mathrm{~s}$ and the red (gray) symbols to a playing duration of $240 \mathrm{~s}$. The linear regressions for maxima and minima are shown as solid and dashed lines respectively. The time for each point was taken as the middle of each cycle used to calculate $Z_{\text {bore }}(f)$. Data are for lab temperature $26.3 \pm 0.3{ }^{\circ} \mathrm{C}$ and relative humidity $55 \pm 6 \%$.

\section{RESULTS AND DISCUSSION}

When the player commences playing an instrument that had previously been flushed with dry air and equilibrated in the lab at ambient temperature and humidity, the input impedance $Z_{\text {bore }}$ of the instrument can be affected via the following three mechanisms.

The first is that the temperature $T$ rises in the bore and the gas composition changes; this will change the density $\rho$ of the air in the bore. (The gas composition and temperature will vary with time and also with distance along the bore.) The speed of sound is given by $c=\sqrt{\gamma P_{0} / \rho}$, where $P_{0}$ denotes atmospheric pressure and $\gamma$ denotes the heat capacity ratio, whose variation with composition is shown later to be several times less than that due to changes in density. For a simple open cylindrical duct of effective length $L$, the frequencies of impedance extrema are given by $f_{\max }=(2 n+1) c / 4 L$ and $f_{\min }=n c / 2 L$ where $\mathrm{n}=$ $0,1,2,3, \ldots$ Thus, all else equal, an increase in $\rho$ will decrease the resonance frequencies.

The characteristic impedance $Z_{0}$ of a simple cylindrical duct is given by $Z_{0}=\sqrt{\rho \gamma P_{0}} / A$, where $A$ denotes the cross-sectional area of the duct. An increase in $\rho$ or $\gamma$ will increase the magnitude of the characteristic impedance, $Z_{0}$ and consequently increase the magnitudes of 
the maxima and minima.

The second occurs when water vapour in the bore has begun to condense on the walls: this can increase the acoustic losses (Hickey et al., 2000; Coltman, 2003). All else equal, increased acoustic losses will decrease the magnitude of maxima, increase the magnitude of minima and broaden the resonances, i.e. reduce their $\mathrm{Q}$ factors.

The third is a much smaller effect due to loss by sound radiation in air as a function of composition; this should be negligible in comparison with the wall losses (Morse and Ingard, 1968).

\section{A. Measurements at ambient temperature: 26 to $27^{\circ} \mathrm{C}$}

At constant atmospheric pressure, the effects of increasing $\mathrm{T}$ and water concentration in the bore would both on their own lower the density of air and so increase the speed of sound; this would tend to increase the frequency of each bore resonance. However, $\mathrm{CO}_{2}$ concentration in the bore also rises, which tends to lower the speed of sound. (Oxygen concentration also falls, but because $\Theta_{2}$ has a molar mass close to the average for air, the effect of falling $\Theta_{2}$ concentration is expected to be modest. Molar masses for water, air, oxygen, and $\mathrm{CO}_{2}$ are $18,29,32$ and $44 \mathrm{~kg} \cdot \mathrm{kmol}^{-1}$ respectively. Figure 3 shows measurements on a section of the impedance spectrum of the trombone when played for 10 , 30,60 and $240 \mathrm{~s}$. The lowest resonance, which is not played, does not occur in the frequency range of these measurements.

The resonance frequencies initially decrease for short playing durations, until they begin to increase; this is consistent with an initial increase in density produced by increasing $\mathrm{CO}_{2}$ concentration until it is counteracted by increasing $\mathrm{T}$ and humidity. However, from consideration of gas density alone, a decrease in frequency produced by an increase in density would be accompanied by a corresponding increase in the magnitudes of $Z_{0}$ and hence $Z_{\max }$. 
The measurements show that the $Z_{\max }$ actually decrease for longer playing duration, presumably as a consequence of increased losses. The increase in $Z_{\min }$ after $30 \mathrm{~s}$ is also consistent with increased losses. These losses are discussed below.

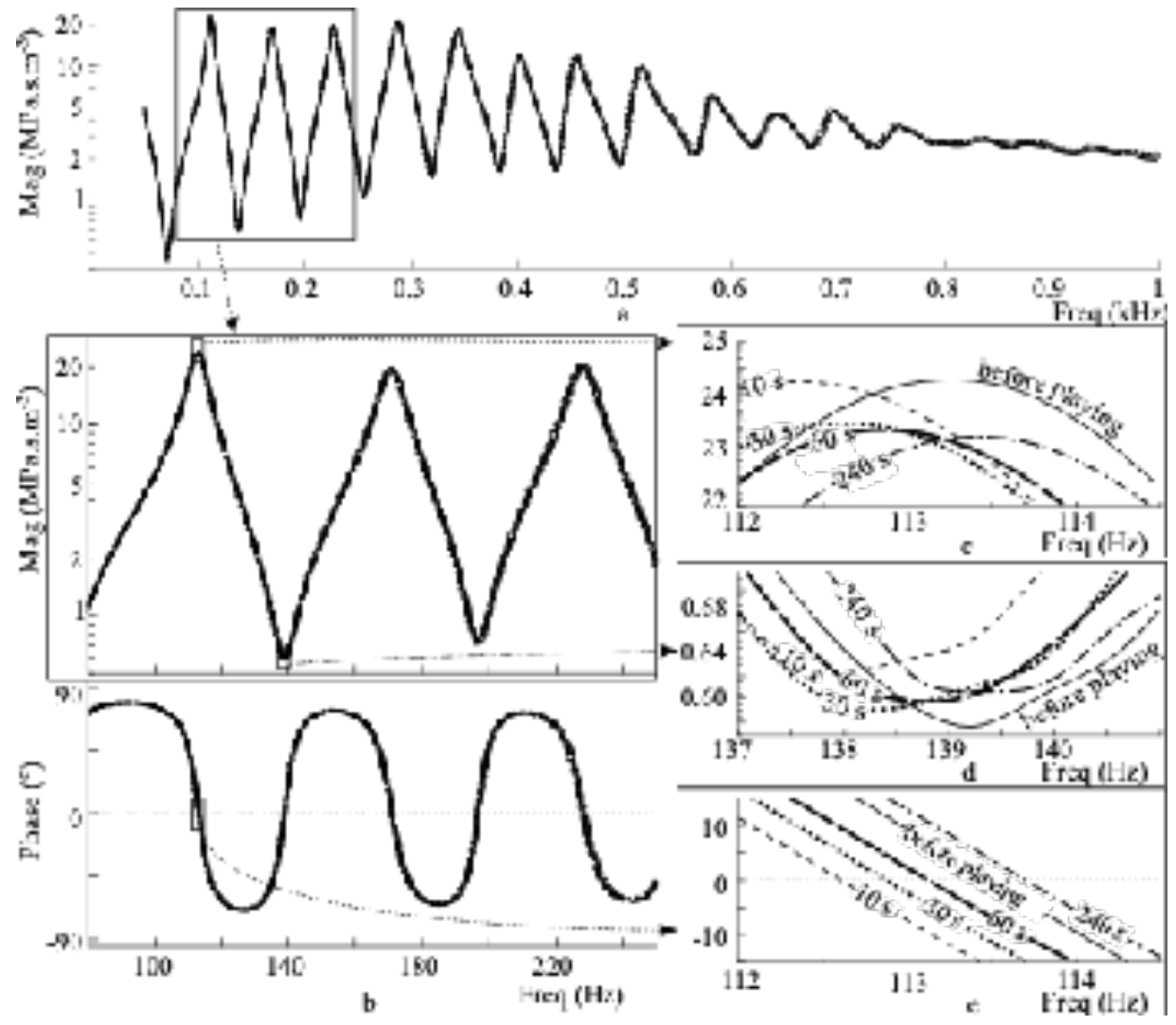

FIG. 3. $+Z_{\text {bore }}(f)+$ measured between $50 \mathrm{~Hz}$ and $1 \mathrm{kHz}$ showing the second and higher resonances (a). A zoom on the resonances two, three and four measured $3 \mathrm{~s}$ after different durations of playing by the same player (b). The insets zoom in on the impedance magnitude maxima (c) and minima (d) and on the phase zero-crossing (e) of the second resonance. 

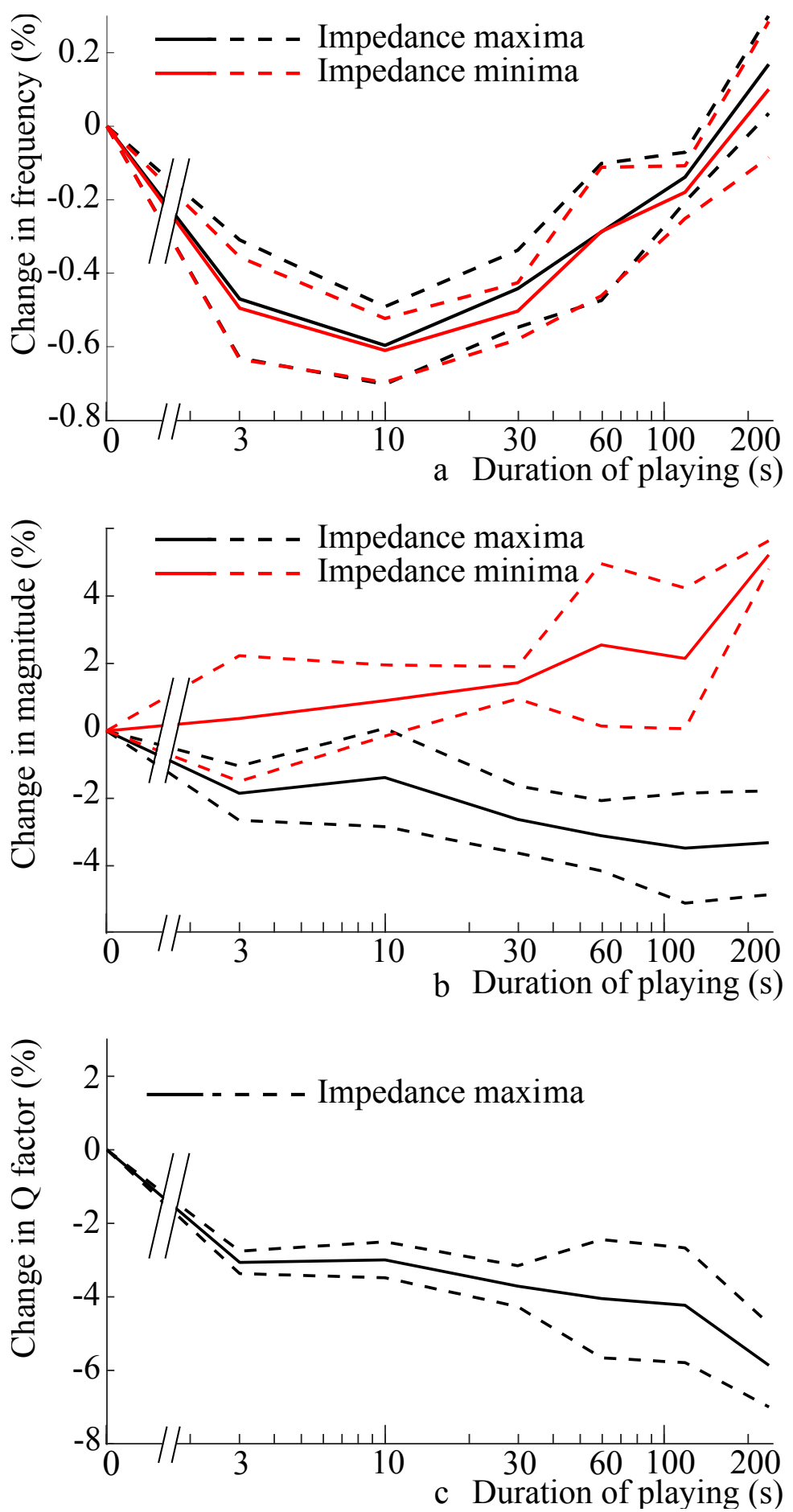

FIG. 4. (Color online) The mean percentage changes in the frequencies (a), magnitudes (b) of the extrema in $Z_{\text {bore }}$ and Q factors (c) of impedance peaks 3 to 7 versus duration of playing (on a $\log$ scale), in a lab at ambient temperature and 55\% relative humidity. The black and red (gray) lines (top and middle) show the variations of, respectively, the corresponding impedance maxima and minima. The dashed lines show \pm one standard deviation. 
Figure 4 shows the average of the data at ambient room temperature obtained by the extrapolation procedure explained in the Methods section for the 36 measurements at $26.3{ }^{\circ} \mathrm{C}$ and the 40 measurements in a preliminary study at $27{ }^{\circ} \mathrm{C}$, reported in a conference paper (Boutin et al., 2013). It shows the mean percentage changes in the frequencies and magnitudes of the peaks in $Z_{\text {bore }}$ after playing for 3,10, 30, 60, 120 and $240 \mathrm{~s}$.

Both $f_{\max }$ and $f_{\min }$ initially decrease when playing starts, the lowest frequency being produced after playing for $10 \mathrm{~s}-$ see Fig. $4 \mathrm{a}$. Over this short time, the effect of $\mathrm{CO}_{2}$ on the speed of sound dominates over those of temperature and humidity. For the longer durations, the players inhaled at least once. Consequently, the concentration and effect of $\mathrm{CO}_{2}$ did not increase monotonically over time, while the effects of temperature and humidity presumably did increase and eventually more than compensated for the effect of $\mathrm{CO}_{2}$. This is consistent with the observed slow increase in $f_{\max }$ and $f_{\text {min }}$ after $10 \mathrm{~s}$. (The fact that increased $\mathrm{CO}_{2}$ concentration significantly cancels the effect of increased temperature and humidity is a fortunate one for wind players.) Changes in density should affect $f_{\max }$ and $f_{\min }$ equally; over all measurements the ratio of the changes in $f_{\min }$ to the preceding $f_{\max }$ was $0.99967 \pm$ 0.00126

There is a nearly monotonic decrease in the magnitude of the impedance maxima with increasing playing time and the magnitude of the minima increases in an almost monotonic fashion - see Fig. 4b. After 240 s duration of playing, the magnitudes of the extrema have changed by around $4 \%$, in opposite directions. Assuming that the observed initial decrease in frequency is caused by an increase in density, a corresponding increase in $Z_{0}$, and hence $Z_{\max }$ and $Z_{\min }$, would be expected. The change due to density can be calculated from Fig. 4a, neglecting that due to specific heat ratio. The effect of density on $Z_{0}$ can then be removed from the measured magnitude of the impedance extrema, leaving only the changes produced 
by increased losses - see Fig. 5. Changes in the wall losses are expected to be roughly proportional to changes in the magnitude of the impedance, consequently the wall losses have increased by around $4 \%$ after 240 s of playing.

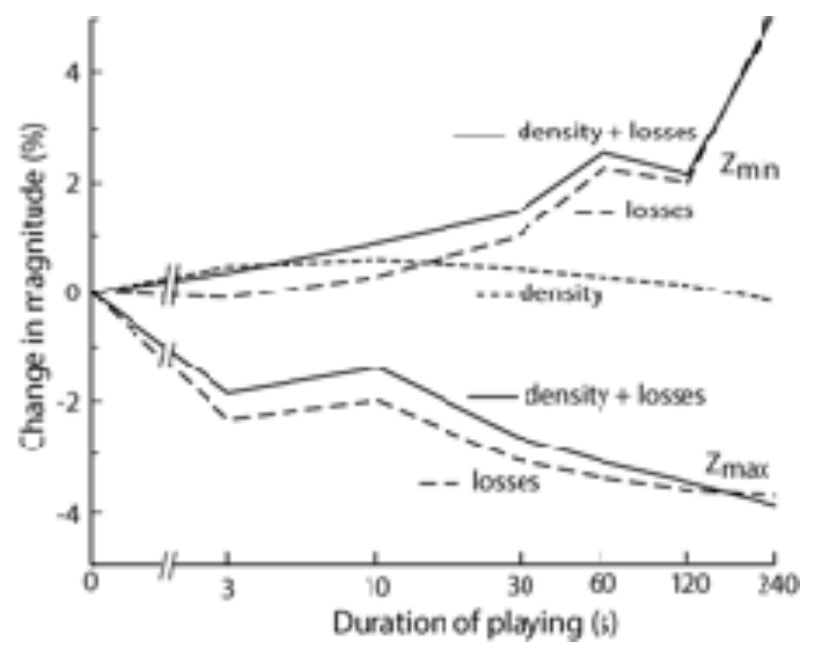

FIG. 5. Separation of the percentage changes in the mean values of $Z_{\max }$ and $Z_{\min }$ into those caused by density changes and those caused by changes in the losses, at ambient temperature.

Increased losses would increasingly broaden both maxima and minima, with increased time of playing consequently producing decreases in the quality factor $Q$ of the resonances. Percentage changes in the average value of $Q$ are shown in Fig. 4c. From 380 peaks where $Q$ and $Z_{\max }$ were both measured, a linear fit found the relationship between the change in $\mathrm{Q}$ factor and the change in $Z_{\max }$ due to losses was $\Delta Q=0.76\left(\mathrm{~m}^{3} \mathrm{~s}^{-1} \mathrm{MPa}^{-1}\right) \Delta Z_{\max }-0.02$ at ambient temperature $\left(\mathrm{r}^{2}=0.57\right)$.

Hickey et al. (2000) and Coltman (2003) (see also Slaton, 2004) identify a significant energy loss mechanism in instrument bores when water is present and the humidity is at or close to saturation: water can condense and evaporate in each cycle of a standing wave. To eliminate condensation, a set of measurements were conducted in a lab that had been heated to $39^{\circ} \mathrm{C}$, with the instrument equilibrated at that temperature. 


\section{B. Measurements at elevated temperature: $39^{\circ} \mathrm{C}$}

The $39{ }^{\circ} \mathrm{C}$ measurements show that the mean frequencies of the maxima and minima are initially reduced only slightly, if at all, for most playing durations (see Fig. 6a). However, the changes are generally not statistically significant at the $95 \%$ confidence level. In this experiment, a negligible change in temperature with playing time is expected. However, the fact that the initial decrease in frequency at $39^{\circ} \mathrm{C}$ is smaller than that at ambient temperature can be explained by humidity: the water concentration at saturation is 1.83 times higher at body temperature $\left(37^{\circ} \mathrm{C}\right.$ ) than at $26.3{ }^{\circ} \mathrm{C}$ (Engineering Toolbox, 2020), so the humidity offsets the $\mathrm{CO}_{2}$-induced fall in frequency to a greater extent at the higher temperature.

The rise in frequency towards $240 \mathrm{~s}$ might be explained if the player at this stage had reached his steady-state respiration, breathing more often at high temperature than he would for shorter phrases or lower temperature, and were thus keeping the $\mathrm{CO}_{2}$ concentration lower than for shorter intervals.-

The smaller changes in resonant frequencies also mean that changes in impedance magnitude due to density changes will be smaller than at ambient temperature: see Fig. 7 .

However, for playing durations greater than $10 \mathrm{~s}$, rather than decreasing as for ambient temperature, the mean of $Z_{\max }$ now slightly increases with increasing duration of playing, although this increase is not statistically significant at the $95 \%$ level. The air in the lungs at 37 ${ }^{\circ} \mathrm{C}$ is close to saturated at this temperature. The relative humidity of this air falls further below saturation when it enters the warmer instrument at $39{ }^{\circ} \mathrm{C}$. So, no condensation is expected inside a trombone at $39^{\circ} \mathrm{C}$ and hence, unlike at ambient temperature, there is no expected loss due to condensation-evaporation cycles, even though the humidity rises.

The $Q$ values for $39{ }^{\circ} \mathrm{C}$ fall by about $2 \%$ in the first $3 \mathrm{~s}$ (as soon as the bore is largely 
filled with exhaled air) and then remain steady for longer durations - see Fig. 6c. This is in contrast to the $Q$ values at ambient temperature that continue to fall as playing time increases. This latter behavior is what the condensation-induced losses would predict as successively more of the bore walls acquired condensation.
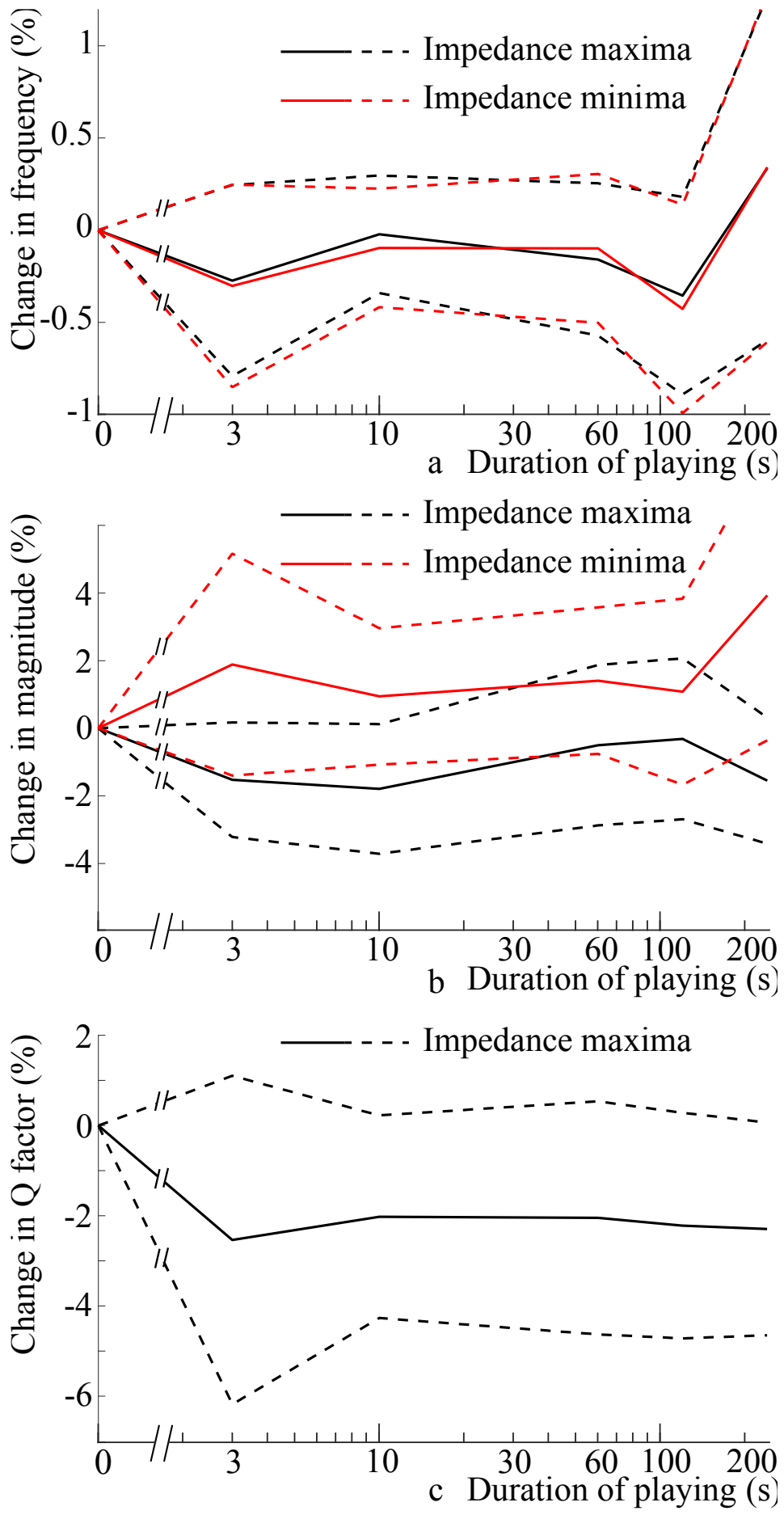

FIG. 6. (Color online) The mean percentage changes in the frequencies (a), magnitudes (b) of 
the extrema in $Z_{\text {bore }}$ and Q factors (c) of impedance peaks 3 to 7 versus duration of playing (on a log scale), in a lab at $39^{\circ} \mathrm{C}$ and $45 \%$ relative humidity. The black and red (gray) lines (top and middle) show the variations of the corresponding impedance maxima and minima respectively. The dashed lines show \pm one standard deviation.

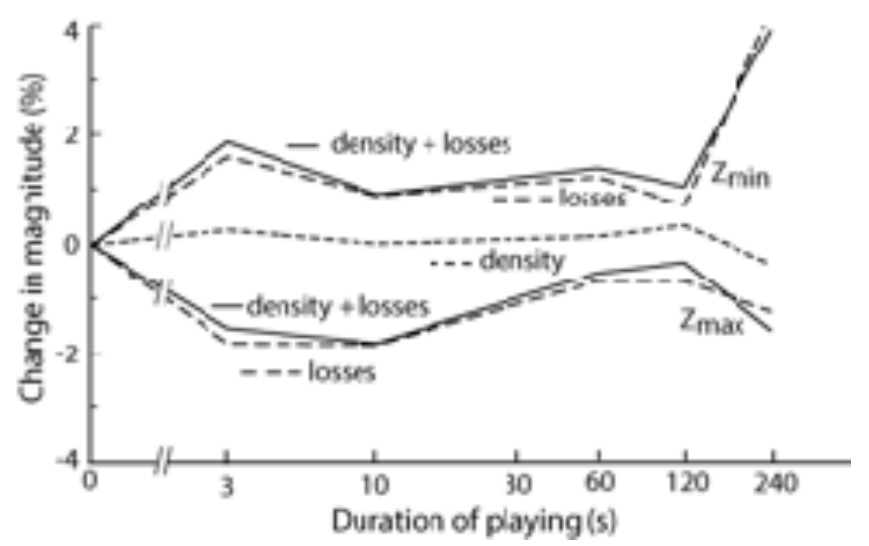

FIG. 7. Separation of the percentage changes in the mean values of $Z_{\max }$ and $Z_{\min }$ into those caused by density changes and those caused by changes in the losses, at $39{ }^{\circ} \mathrm{C}$.

The results of the experiments reported here are qualitatively explained above in terms of the known effects of gas composition and temperature on the speed of sound. Simple estimates allow the changes in Figs. $4 \& 6$ to be related to the underlying variables. $\mathrm{CO}_{2}$ (molar mass $44 \mathrm{~kg} . \mathrm{kmol}^{-1}$ ) and $\mathrm{H}_{2} \mathrm{O}$ have respectively 44/29 and 18/29 times the mass of a mole of air. $\mathrm{O}_{2}$ has a molar mass $\left(32 \mathrm{~kg} . \mathrm{kmol}^{-1}\right)$ not far from the average for air (29 $\mathrm{kg} \cdot \mathrm{kmol}^{-1}$ ) and so depleting oxygen concentration is expected to have relatively little effect. At constant temperature, the speed of sound is inversely proportional to the square root of the density of air, to a good approximation. The values of $\gamma$ for $\mathrm{CO}_{2}, \mathrm{H}_{2} \mathrm{O}$ and dry air are respectively 1.289, 1.330 and 1.400 (Bhattacharjee, 2020; Engineering Toolbox, 2020). The speed of sound is given by $c=\sqrt{\gamma P_{0} / \rho}$ or, for constant pressure,

$$
1+\frac{\Delta c}{c}=\left(1+\frac{\Delta \gamma}{\gamma}\right)^{\frac{1}{2}}\left(1+\frac{\Delta \rho}{\rho}\right)^{-\frac{1}{2}}
$$


At constant temperature and pressure, consider only small increases $\Delta C$ and $\Delta H$ in fractional molar concentrations of $\mathrm{CO}_{2}$ and $\mathrm{H}_{2} \mathrm{O}$ in the air respectively, where these gases replace air in the usual mixture of nitrogen and oxygen. The adiabatic ratio is changed by

$$
\Delta \gamma=\Delta C\left(\gamma_{\mathrm{CO}_{2}}-\gamma_{\text {air }}\right)+\Delta H\left(\gamma_{\mathrm{H}_{2} \mathrm{O}}-\gamma_{\mathrm{air}}\right)
$$

and the density by an analogous expression. From substitution and retaining only zeroth and first order terms, the speed of sound is increased by a factor $1-0.30 \Delta C+0.16 \Delta H$. (If instead $\mathrm{CO}_{2}$ and $\mathrm{H}_{2} \mathrm{O}$ replace pure nitrogen or oxygen, the numerical results are only a little different.)

For inhaled and expired air under normal breathing, $\Delta C$ is typically about $4 \%$ by volume or mole (Buszewski et al., 2007), which on its own would give a fall in the speed of sound of a little more than $1 \%$. However, the difference is likely to be smaller on average in this experiment, because the players began exhaling into the instrument as soon as they finished inhaling, which would give exhaled gas whose initial $\mathrm{CO}_{2}$ concentration would be lower than normal.

If the temperature change were $\Delta T$ and uniform, the speed of sound would increase by a factor about $1+\frac{\Delta T}{2 T}$. Taking $T \sim 300 \mathrm{~K}$, and using $\Delta T$ for an effective, overall change in $T$, the speed of sound and so the frequency are proportional to $1+\frac{\Delta T}{600 \mathrm{~K}}$. So the proportional change in frequency would be $\Delta \mathrm{f} / \mathrm{f}=\Delta T / 600 \mathrm{~K}-0.30 \Delta C+0.16 \Delta H$. Thus a $1 \%$ increase in frequency would require either $\Delta T \cong+6^{\circ} \mathrm{C}, \Delta C \cong-3 \%$, or $\Delta H \cong+6 \%$ or some linear combination of these. For example, Fig. 4 could be explained by a $\mathrm{CO}_{2}$ concentration of 2-4\% that is gradually offset by a combination of a few degrees increase in effective temperature and a few percent increase in water concentration. Once there is condensation, a rise 
in $T$ usually means a rise in absolute humidity, because the water content at saturation rises strongly with $T$.

\section{CONCLUSIONS}

Playing the dry instrument at room temperature, the frequency of the impedance peaks of the bore fall by about $0.6 \%$ in the first 10 seconds, as the density of the air in the bore increases. This is a result of $\mathrm{CO}_{2}$ in the breath more than compensating for increased temperature and humidity. Over the next few minutes, the frequencies rise to close to or a little above their original values, as the effects of humidity and temperature overcome that of the $\mathrm{CO}_{2}$. The magnitude and quality factors of impedance maxima decrease with increasing playing time, consistent with enhanced wall losses due to water condensing in the bore. This effect is attributed to losses associated with latent heat exchange between humid air and wet walls. Playing in a room at $39{ }^{\circ} \mathrm{C}$, and therefore without condensation, the effect on the magnitudes of impedance extrema and the Q factor is substantially reduced.

\section{ACKNOWLEDGMENTS}

We thank the Australian Research Council for support and our volunteer subjects.

Backus, J. (1976). "Input impedance curves for the brass instruments," J. Acoust. Soc. Am. $\mathbf{6 0}(2), 470-480$.

Balasubramanian, S., and Kausel, W. (2015). "Pitch shifts in wind instruments due to changes in air composition," Proceedings of the Third Vienna Talk on Music Acoustics, Vienna, Austria, pp. 16-19.

Bhattacharjee. S. "Properties of various ideal gases (at 300 K)" (San Diego State Univ.) https://www.ohio.edu/mechanical/thermo/property_tables/gas/idealgas.html downloaded 19 July 2020. 
Boutin, H., Fletcher, N., Smith, J., and Wolfe, J. (2013). "Lip motion, the playing frequency of the trombone and upstream and downstream impedances" Proceedings of SMAC conference, SMAC2013, Stockholm, Sweden, pp. 483-489.

Boutin, H., Fletcher, N., Smith, J., and Wolfe, J. (2015). "Relationships between pressure, flow, lip motion and upstream and downstream impedances for the trombone," J. Acoust. Soc. Am. 137, 1195-1209.

Boutin, H., Smith J. and Wolfe, J. (2020). "Trombone lip mechanics with inertive and compliant loads (“lipping up and down”)," J. Acoust. Soc. Am. 147, 4133-4144.

Braden, A. C. P., Newton, M. J., and Campbell, D. M. (2009). "Trombone bore optimization based on input impedance targets," J. Acoust. Soc. Am. 125, 2404-2412.

Buszewski, B., Kesy, M., Ligor, T., and Amann, A. (2007). "Human exhaled air analytics: biomarkers of diseases," Biomedical Chromatography 21(6), 553-566.

Caussé, R., Kergomard, J., and X. Lurton, X. (1984). "Input impedance of brass musical instruments - Comparison between experiment and numerical models," J. Acoust. Soc. Am. 75, $241-254$.

Coltman, J. W. (2003). "Acoustical losses in wet instrument bores," J. Acoust. Soc. Am. 114, 1221.

Engineering Toolbox (2020). "Ratio of specific heat of gases" https:// www.engineeringtoolbox.com/specific-heat-ratio-d 608.html (downloaded 19 July 2020).

Fuks, L. (1996). "Prediction of pitch effects from measured CO2 content variations in wind instrument playing," KTH Dept Speech, Music and Hearing, Quarterly Progress and Status Reports 37, 37-43.

Fuks, L. (1997). "Measurements of exhaled air effects in the pitch of wind instruments," KTH Dept Speech, Music and Hearing, Quarterly Progress and Status Reports 38, 7-11. 
Hickey, C.J., Raspet, R., and Slaton, W.V. (2000). "Effects of thermal diffusion on sound attenuation in evaporating and condensing gas-vapor mixtures in tubes," J. Acoust. Soc. Am. 107, 1126-1130.

Morse, P.M. and Ingard, K.U. (1968). Theoretical Acoustics, McGraw-Hill, New York, NY. pp 270-300.

Smith, J. R., Henrich, N., and Wolfe, J. (1997). "The acoustic impedance of the Bøhm flute: Standard and some non-standard fingerings," Proceedings of Institute of Acoustics 19, pp. 315-320.

Slaton, W.V. (2004). "Comment on "Acoustical losses in web instrument bores" [J. Acoust. Soc. Am. 114, 1221 (2002)] (L)," J. Acoust. Soc. Am. 115(3), 971-972.

Young, R. W. (1946). "Dependence of tuning of wind instruments on temperature," J. Acoust. Soc. Am. 17(3), 187-191. 